\title{
Unexpectedly Promoting Effect of Carbon Nanotubes Grown During the Non-oxidative Coupling of Methane over Copper Catalysts
}

\author{
Zhi-Yan Zeng ${ }^{1}$, Jian Chen ${ }^{2}$, Jarrn-Horng Lin ${ }^{1}$ * \\ ${ }^{1}$ Department of Materials Science, National University of Tainan, 33, Sec. 2, Shu-lin St., Tainan \\ ${ }^{2}$ Department of Materials Science and Engineering, Sichuan University of Science and Engineering, Key Lab Material Correction and Protection, Zigong, \\ 643000, People's Republic of China \\ *Corresponding Author. Email: janusjhlin@mail.nutn.edu.tw \\ Received: 20 November 2018, Accepted: 28 December 2018, Published Online: 31 December 2018
}

Citation Information: Zhi-Yan Zeng, Jian Chen, Jarrn-Horng Lin. Frontier Research Today 2018;1:1007. doi: 10.31716/frt.201801007 Cite in Other Styles

ABSTRACT: One of the challenges for the non-oxidative coupling of methane (NOCM) is to effectively remove the deposited coke over catalysts owing to the over-dehydrogenation of methane. Herein, we show that an insitu growth of carbon nanotubes (CNTs) instead of coke were observed during NOCM over a CuSO${ }_{4} / \gamma-\mathrm{Al}_{2} \mathrm{O}_{3}$ catalyst. The as-grown CNTs depict an unexpected promoting effect for NOCM with a highest activity of 0.48 mol kg cat ${ }^{-1} \cdot \mathrm{h}^{-1}$, and maintained $85 \%$ activity after $200 \mathrm{~h}$ running time. The equilibrium methane conversion is 9.8\% with a selectivity of $78.2 \%$ for $\mathrm{C}_{2}\left(\mathrm{C}_{2} \mathrm{H}_{4}+\mathrm{C}_{2} \mathrm{H}_{6}\right)$ products. Highly dispersed Cu nanoparticles distributed on the top of CNTs measured by transmission electron microscopy is proposed to result in high catalyst stability during NOCM for $200 \mathrm{~h}$ instead of deactivation in several hours. Here, we firstly prove that the as-grown CNTs can promote the catalytic activity of NOCM instead of deactivation by coking over catalysts.

Keywords: Carbon nanotube; Non-oxidative coupling of methane; Copper catalysts; Promoting effect; Catalytic activity

Highlight
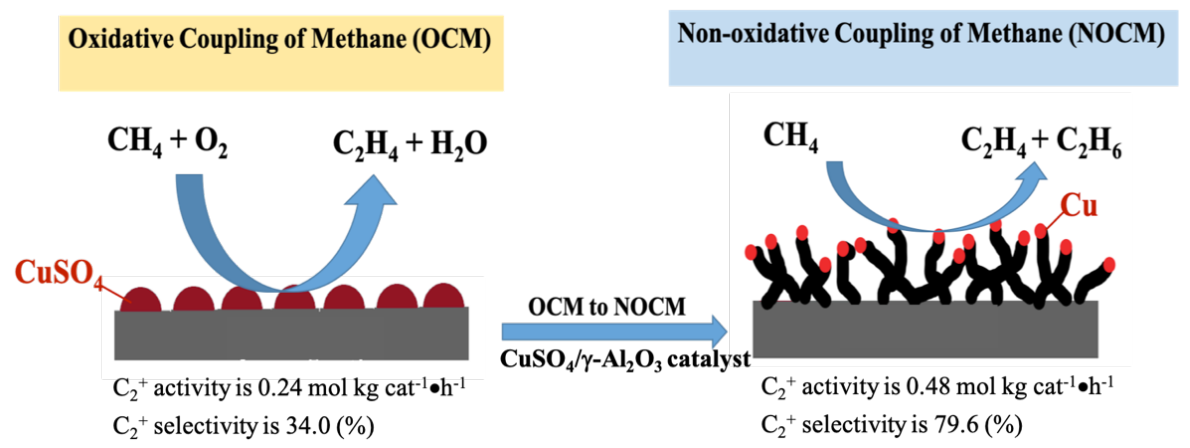

We develop an unique catalyst-5.0 wt $\% \mathrm{CuSO}_{4} / \gamma-\mathrm{Al}_{2} \mathrm{O}_{3}$ which can conduct both OCM and NOCM. The maximum activity of NOCM is near twice of that for OCM. The as-grown MWCNTs in NOCM is firstly reported to be unexpected promoter over $5.0 \mathrm{wt} \% \mathrm{CuSO}_{4} / \gamma-\mathrm{Al}_{2} \mathrm{O}_{3}$ catalyst. The yield of the activity is $0.48 \mathrm{~mol} \mathrm{kgcat}^{-1}$ hour ${ }^{-1}$ with a $\mathrm{C}_{2}$ selectivity of $78.2 \%$ and an equilibrium methane conversion of $9.8 \%$ at $800{ }^{\circ} \mathrm{C}$. Moreover, a 200-h catalytic testing, the activity can maintain at $85 \%$ of the highest value.

\section{INTRODUCTION}

The direct, non-oxidative conversion of methane (NOCM) into light olefins or aromatics, e.g. ethylene, ethane and benzene, is a highly attractive issue for academia and industry. Recently, several advancements have been reported to develop new concepts of catalyst systems for effectively direct converting methane into aromatics or ethylene with remarkable activities, selectivity, and durabili$\operatorname{ty}^{1,2}$. Moreover, the cost of the production of ethylene using NOCM was reported less than one fifth of that by using the stream cracking of crude oil ${ }^{3}$. Additionally, the main merits of NOCM can get rid of the complicated separation of products without oxygen as well as the generation of $\mathrm{CO}_{2}$. These evidences show that direct conversion of methane is promisingly more economical and environmentally friendly.
However, two main challenges for NOCM are needed to be overcome: (i) the activation of methane ( $\mathrm{C}-\mathrm{H}$ bond strength is $434 \mathrm{~kJ} / \mathrm{mol})$ need high temperatures $\left(>700{ }^{\circ} \mathrm{C}\right)$, and (ii) catalysts were deactivated quickly through kinetically preferred generation of coke. Therefore, numerous studies conducted the oxidative coupling of methane (OCM) from $1980 \mathrm{~s}^{4-8}$. Usually, the presence of oxygen results in the overoxidation of methane, leading to an immense amount of the thermodynamically stable products carbon dioxide and water. Obviously, the carbon utilization efficiency of OCM is relatively low. Thus, a practical route for OCM is not available so far. Listed reactions (1)-(4) of OCM can be represented as

$2 \mathrm{CH}_{4}(\mathrm{~g})+1 / 2 \mathrm{O}_{2}(\mathrm{~g}) \rightarrow \mathrm{C}_{2} \mathrm{H}_{6}(\mathrm{~g})+\mathrm{H}_{2} \mathrm{O}(\mathrm{g}) \Delta \mathrm{H}^{\mathrm{o}}{ }_{298 \mathrm{~K}}=-177 \mathrm{kJmol}^{-1}(1)$

$\mathrm{C}_{2} \mathrm{H}_{6}(\mathrm{~g})+1 / 2 \mathrm{O}_{2}(\mathrm{~g}) \rightarrow \mathrm{C}_{2} \mathrm{H}_{4}(\mathrm{~g})+\mathrm{H}_{2} \mathrm{O}(\mathrm{g}) \Delta \mathrm{H}^{0}{ }_{298 \mathrm{~K}}=-105 \mathrm{kJmol}^{-1}$

$\mathrm{CH}_{4}(\mathrm{~g})+3 / 2 \mathrm{O}_{2}(\mathrm{~g}) \rightarrow \mathrm{CO}(\mathrm{g})+2 \mathrm{H}_{2} \mathrm{O}(\mathrm{g}) \Delta \mathrm{H}^{\mathrm{o}}{ }_{298 \mathrm{~K}}=-136 \mathrm{kJmol}^{-1}$ 
$\mathrm{CH}_{4}(\mathrm{~g})+2 \mathrm{O}_{2}(\mathrm{~g}) \rightarrow \mathrm{CO}_{2}(\mathrm{~g})+2 \mathrm{H}_{2} \mathrm{O}(\mathrm{g}) \Delta \mathrm{H}^{\mathrm{o}}{ }_{988 \mathrm{~K}}=-189 \mathrm{kJmol}^{-1}$

Recently, Guo et al. demonstrated a new type of heterogeneous iron catalyst which can directly convert methane (48.1\% conversion) into higher hydrocarbons (> 99\% with ethylene, benzene, and naphthalene) without the formation of coke or unwanted carbon dioxide ${ }^{1}$. However, preparation of the catalyst was complicated and needed high temperature $\left(1700{ }^{\circ} \mathrm{C}\right)$. More recent, Morejudo et al. used a co-ionic membrane reactor to directly transform methane into benzene with a high carbon efficiency of $\sim 80 \%$ at a relative low temperature of $700{ }^{\circ} \mathrm{C}^{2}$. Moreover, several reports have demonstrated that NOCM is a promising route to form light olefins or aromatics ${ }^{9-15}$. The main reactions of NOCM are described as

$$
\begin{aligned}
& \mathrm{CH}_{4}(\mathrm{~g}) \rightarrow 1 / 2 \mathrm{C}_{2} \mathrm{H}_{6}(\mathrm{~g})+1 / 2 \mathrm{H}_{2}(\mathrm{~g}) \Delta \mathrm{H}^{\mathrm{o}}{ }_{298 \mathrm{~K}}=65 \mathrm{kJmol}^{-1} \\
& \mathrm{CH}_{4}(\mathrm{~g}) \rightarrow 1 / 2 \mathrm{C}_{2} \mathrm{H}_{4}(\mathrm{~g})+\mathrm{H}_{2}(\mathrm{~g}) \Delta \mathrm{H}^{\mathrm{o}}{ }_{298 \mathrm{~K}}=101 \mathrm{kJmol}^{-1} \\
& \mathrm{C}_{2} \mathrm{H}_{6}(\mathrm{~g}) \rightarrow \mathrm{C}_{2} \mathrm{H}_{4}(\mathrm{~g})+\mathrm{H}_{2}(\mathrm{~g}) \Delta \mathrm{H}^{\mathrm{o}}{ }_{298 \mathrm{~K}}=135 \mathrm{kJmol}^{-1}
\end{aligned}
$$

Comparison of OCM, the main merit of NOCM is a suppression of over-oxidation of methane. This will significantly improve the selectivity of higher hydrocarbons instead of carbon dioxide. However, how to control the catalysis system preventing over-dehydrogenation of methane is a key step to avoid the formation of coke in $\mathrm{NOCM}^{1,}$ ${ }^{2,9-15}$. Therefore, the design concepts for active catalysts or reaction systems should avoid completely dehydrogenation of methane in NOCM. Conventionally, the as-generated carbon materials during NOCM were reported that will led to a major deactivation in catalytic activity. The active metal components of catalysts were covered with the as-grown carbon materials with highly graphitic structures, e.g. coke, graphite or carbon nanofibers, and forfeited their catalytic activity gradually ${ }^{1,2,9-15}$. The catalytic activities of catalysts for NOCM will deactivate soon, normally in less several hours. Therefore, the design concepts of the conventional catalysts were focused on preventing the formation of carbonaceous materials during the reaction conditions in NOCM. As we know, the promotion effect of the as-grown carbonaceous materials in NOCM was not reported yet. Herein, we present a new finding that the as-grown carbon nanotubes (CNTs) during NOCM over $\mathrm{CuSO}_{4} / \gamma-\mathrm{Al}_{2} \mathrm{O}_{3}$ catalysts can promote the catalytic activity with high $\mathrm{C}_{2}\left(\mathrm{C}_{2} \mathrm{H}_{4}+\right.$ $\mathrm{C}_{2} \mathrm{H}_{6}$ ) yields for a $200 \mathrm{~h}$ test. The in-situ multi-walled CNTs chased from Air Liquide.

\section{Preparation of copper catalysts}

Copper catalysts were prepared by wet impregnation according to our earlier work ${ }^{16,17}$. Typically, copper (II) sulfate pentahydrate $(0.1 \mathrm{~g})$ was dissolved in $10 \mathrm{~mL}$ pure water with a vigorous magnetic stirring under air. The copper solution was added into $\gamma-\mathrm{Al}_{2} \mathrm{O}_{3}$ powder $(0.4 \mathrm{~g})$ step by step with a potent stirring by hand for $30 \mathrm{~min}$. The final slurry solution was dried in oven at $120{ }^{\circ} \mathrm{C}$ under air overnight. The final loading of $\mathrm{Cu}$ was $5.0 \pm 0.2 \mathrm{wt} . \%$, which was determined by atomic adsorption spectroscopy and inductively coupled plasma mass spectrometry (ICP-MS, PE-SCIEX ELAN 6100 DRC).

\section{Oxidative conversion of methane (OCM)}

Catalytic activities were carried out in a continuous flow, fixed-bed quartz tube reactor. In all OCM tests, $0.1 \mathrm{~g}$ of the prepared copper catalysts-5.0 wt $\% \mathrm{CuSO}_{4} / \gamma-\mathrm{Al}_{2} \mathrm{O}_{3}$ was put in the reactor. The reaction temperatures were adjusted between $700-1100{ }^{\circ} \mathrm{C}$. The feed gas is a mixture of argon diluted methane $\left(\mathrm{CH}_{4} / \mathrm{O}_{2} / \mathrm{Ar}=60 / 1 / 19\right)$ with a flow rate of $40 \mathrm{~mL} / \mathrm{min}$. The effluent gas composition was examined by an online gas chromatography (GC, Shimadzu GC-2014), which is equipped with an FID detector with HP-DPX5 column (I.D. is $0.53 \mathrm{~mm}, 25 \mathrm{~m}$ in length with a $1.0 \mu \mathrm{m}$ inner coating film). Methane conversion, hydrocarbon products selectivity and carbon deposition were calculated through the carbon balance, following previously reported methods $^{13-15}$.

\section{Non-oxidative conversion of methane (NOCM)}

Catalytic activities were carried out in a continuous flow, fixed-bed quartz tube reactor. In all NOCM tests, $0.1 \mathrm{~g}$ of the prepared copper catalysts $-5 \mathrm{wt} \% \mathrm{CuSO}_{4} / \gamma-\mathrm{Al}_{2} \mathrm{O}_{3}$ was put in the reactor. The reaction temperatures were adjusted between $700-1100{ }^{\circ} \mathrm{C}$. The feed gas is a mixture of argon diluted methane $\left(\mathrm{Ar} / \mathrm{CH}_{4}=1 / 3\right)$ with a flow rate of $40 \mathrm{~mL} / \mathrm{min}$. The effluent gas composition analysis and characterization of methane conversion, product distribution were carried out the same standards of OCM. growth following a tip-growth model through $\mathrm{Cu}$ nanoparticles (NPs) during the NOCM reaction was observed. The highly-dispersed $\mathrm{Cu}$ NPs on the top of the as-grown MWCNTs conducted an admirable activity of NOCM with a remarkable resistance of deactivation. These results present new concepts for NOCM.

\section{METHODS}

\section{Materials}

Copper (II) sulfate pentahydrate (99.0\%) was purchased from Signa-Aldrich. $\gamma-\mathrm{Al}_{2} \mathrm{O}_{3}$ powder was supplied by Degussa Co. They were used as received without further purification. Methane, oxygen, air, and argon gas were pur-

\section{Catalyst characterization}

Scanning electron microscopy (SEM) analysis was conducted using a JEOL JSM-6700F. Transmission electron microscopy (TEM, JEOL AEM-300 and JEM-2100) equipped with an energy dispersive spectrometer (EDS) were used to investigate the micro- and nano-scale structural morphologies of the as-grown samples and perform elemental analyses. High resolution TEM Images were performed on to investigate the micro- and nano-scale structural morphologies of $\mathrm{Cu}$ NPs. The weight percent of the as-grown carbon materials was analyzed by a thermogravimeter analyzer (TGA, TA-Q500). The oxidative characteristics of the samples were performed in TGA under air atmosphere (40 $\mathrm{mL} / \mathrm{min}$ ) with a ramp of $40{ }^{\circ} \mathrm{C} / \mathrm{min}$ during $30-800{ }^{\circ} \mathrm{C}$. X-ray 
diffraction data analysis was performed by a Miniflex-III (Rigaku) with a $\mathrm{Cu} \mathrm{K} \alpha$ radiation source $(\lambda=0.15418 \mathrm{~nm})$. Raman scattering spectroscopy (JOBIN-YVON T64000) with a laser excitation wavelength of $532 \mathrm{~nm}$ was used to characterize the graphite-amorphous carbon features of the as-grown carbon materials.

\section{RESULTS AND DISCUSSION}

Previously, sulfate-assisted metal catalysts have been reported with high activities in $\mathrm{OCM}^{18-20}$. The main concepts of these catalysts were regarded that the sulfated-supports, e.g. $\mathrm{SO}_{4}^{-2}-\mathrm{MgO}$ or $\mathrm{SO}_{4}^{-2}-\mathrm{ZrO}_{2}$, can modify surface acidity of catalysts then conduct higher dehydrogenation rate of methane. In OCM, the present of oxygen can prevent over-dehydrogenation of methane and recover active sites of catalysts through the redox process. However, this is a trade-off in OCM and usually leads to a difficult separation of gas products. Therefore, the employment of OCM in practical utilization has been postponed for several decades. Originally, we employ $\mathrm{CuSO}_{4} / \gamma-\mathrm{Al}_{2} \mathrm{O}_{3}$ as a catalyst according to several previous reports for studying OCM. However, we accidentally found that $\mathrm{CuSO}_{4} / \gamma-\mathrm{Al}_{2} \mathrm{O}_{3}$ catalyst displayed remarkable activities in growth of MWCNTs with chemical vapor deposition with methane ${ }^{21}$, ethylene ${ }^{22}$ and ethanol ${ }^{23}$. These reliable evidences lead us to conduct both OCM and NOCM over $\mathrm{CuSO}_{4} / \gamma-\mathrm{Al}_{2} \mathrm{O}_{3}$ catalyst for an adequate reaction time.

To check the activity of the copper sulfated catalyst in the dehydrogenation of methane with and without oxygen, we conducted the activities of OCM firstly and then followed NOCM over $5.0 \mathrm{wt} \% \mathrm{CuSO}_{4} / \gamma-\mathrm{Al}_{2} \mathrm{O}_{3}$ catalyst at $800{ }^{\circ} \mathrm{C}$. In the left-upper panel of Figure 1, which demonstrates that the reactivity of $5.0 \mathrm{wt} \% \mathrm{CuSO}_{4} / \gamma-\mathrm{Al}_{2} \mathrm{O}_{3}$ in OCM was stable and maintained approximately at the space-time yield of $0.24 \mathrm{~mol} \mathrm{kgcat}^{-1}$ hour $^{-1}$ for $2 \mathrm{~h}$. After OCM, oxygen was replaced by argon, then switched to the NOCM mode. It is clearly to find that the reactivity was sharply dropped to zero in $30 \mathrm{~min}$. However, surprisingly, the reactivity can recover gradually in $180 \mathrm{~min}$ of the NOCM process, and reached the maximum of reactivity with a yield of $0.48 \mathrm{~mol}$ $\mathrm{kgcat}^{-1}$ hour $^{-1}$, which is twice of the value of OCM. Moreover, in NOCM process, the first 90 minutes (reaction time during 150-240 minutes in Figure 1), the reactivity presents a lower slope (r1), and the later 60 minutes (reaction time during 240-300 minutes) demonstrates a higher slope (r2) of reactivity. Apparently, the slope of $\mathrm{r} 2$ is higher than r1. This indicates that the recovery behaviors of reactivity over $5.0 \mathrm{wt} \% \mathrm{CuSO}_{4} / \gamma-\mathrm{Al}_{2} \mathrm{O}_{3}$ during NOCM process depict two stages. The first is a slow-growing stage and follows a fast-growing route to reach the maximum of reactivity. We took samples from the reaction times at 30 (a), 60 (b), 120 (c), and 180 (d) min, respectively and examined the surface morphologies of them using SEM, shown in Figure 1(a-d). It is plainly to note that the recovery of catalytic activities over $5.0 \mathrm{wt} \% \mathrm{CuSO}_{4} / \gamma-\mathrm{Al}_{2} \mathrm{O}_{3}$ catalysts is accompanying with the growth of as-grown CNTs or CNFs. The life-time testing was performed for $200 \mathrm{~h}$ at $800{ }^{\circ} \mathrm{C}$, the $5.0 \mathrm{wt} \% \mathrm{CuSO}_{4} /$ $\gamma-\mathrm{Al}_{2} \mathrm{O}_{3}$ was quite stable, and displayed only a slight decline in reaction activity, shown in upper-right panel of Figure 1.

For understanding the morphologies of as-grown fiber-like structures during NOCM over $5.0 \mathrm{wt} \% \mathrm{CuSO}_{4} / \gamma-\mathrm{Al}_{2} \mathrm{O}_{3}$ catalyst at $800{ }^{\circ} \mathrm{C}$, we examined the sample using TEM and selected-area electron diffraction (SAED). Figure 2a displays that $\mathrm{Cu}$ NPs on the top position of MWCNTs are the major product and amorphous carbon (a-C) is formed anywhere on the side-wall of MWCNTs. Figure $2 b$ is an enlarged area of Figure 2a. The SAED on the top position of a typical MWCNT, shown in Figure 2c, depicts that metallic $\mathrm{Cu}$ is the major component of Cu NPs. The results shown in Figure 2a-c reveal that the as-grown MWCNTs were formed through a top-growth model over Cu NPs. Simultaneously, $\mathrm{Cu}$ NPs were highly re-dispersed on the top of MWCNTs,
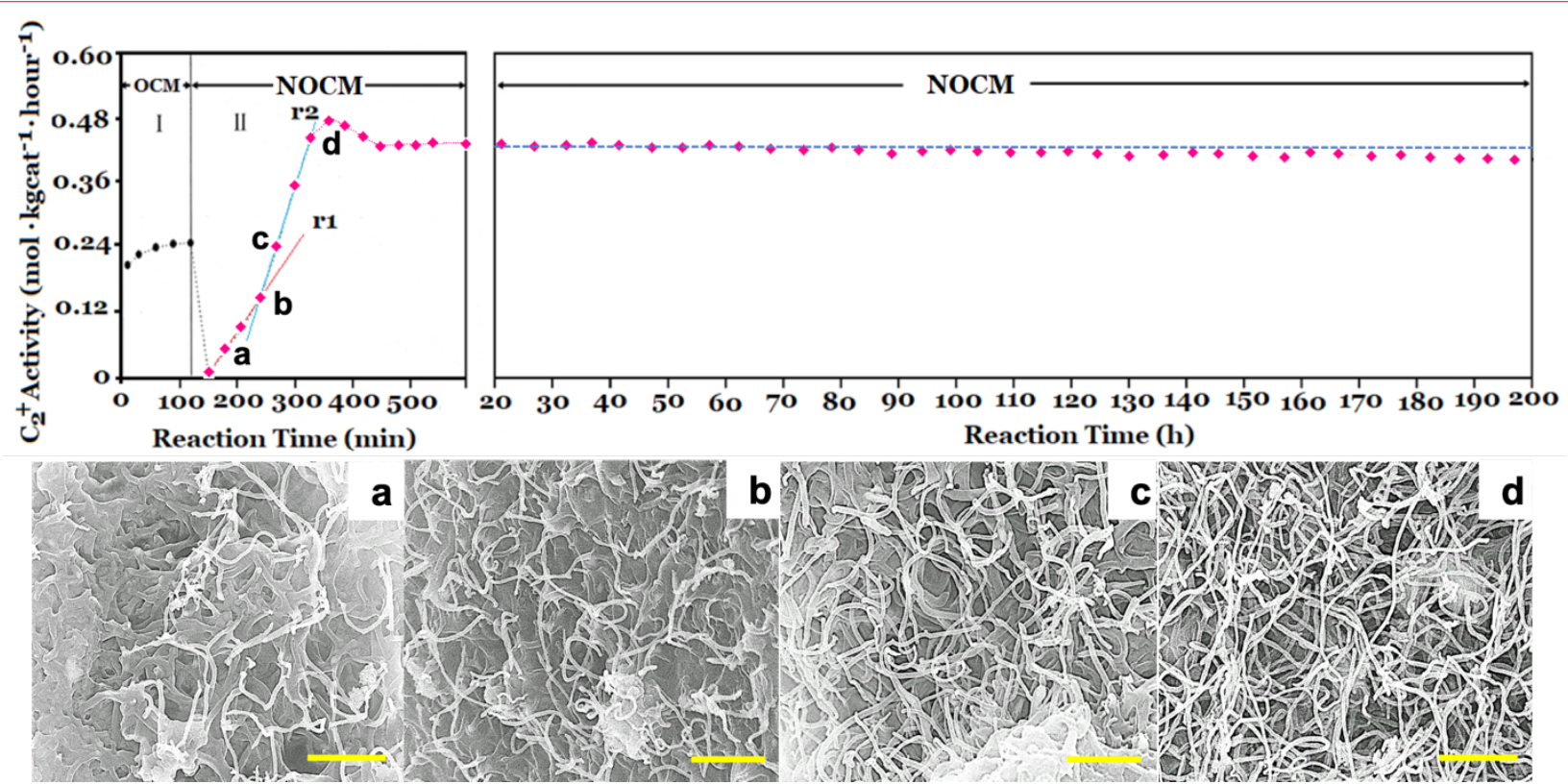

Figure 1. The left-upper and right-upper panels: Catalytic activity of $5.0 \mathrm{wt} \% \mathrm{CuSO}_{4} / \gamma-\mathrm{Al}_{2} \mathrm{O}_{3}$ catalyst for oxidative coupling of methane (OCM) and non-oxidative coupling of methane (NOCM) at $800{ }^{\circ} \mathrm{C}$. For OCM, the feeding gas is a mixture of $\mathrm{CH}_{4} / \mathrm{O}_{2} / \mathrm{Ar}=60 / 1 / 19$ with a flow rate of $40 \mathrm{~mL} / \mathrm{min}$. For NOCM, the feeding gas is a mixture of $\mathrm{CH}_{4} / \mathrm{Ar}=3 / 1$ with a flow rate of $40 \mathrm{~mL} / \mathrm{min}$. (a-d) are SEM images of the different reaction time position in the upper-left panel a-d for NOCM. The scale bar in (a-d) is $0.5 \mu \mathrm{m}$. 


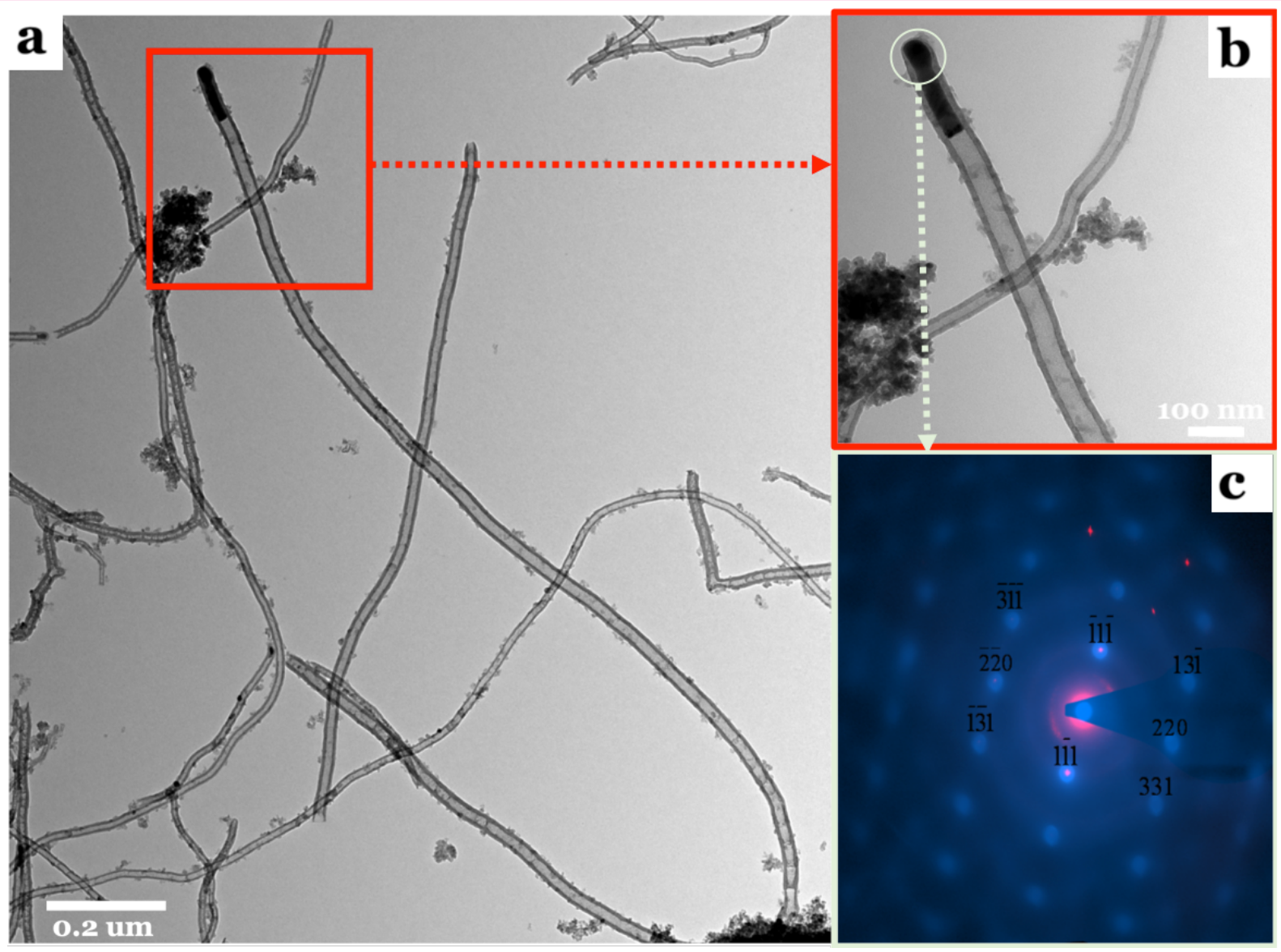

Figure 2. (a) A typical TEM image of the as-grown CNTs, (b) TEM image for the enlarge area of (a), and (c) a selected-area electron diffraction of $\mathrm{Cu}$ NPs of (b), over $5.0 \mathrm{wt} \% \mathrm{CuSO}_{4} / \gamma-\mathrm{Al}_{2} \mathrm{O}_{3}$ catalyst in NOCM at $800{ }^{\circ} \mathrm{C}$ under a mixture of $\mathrm{Ar}$ diluted methane with a flow rate of $40 \mathrm{~mL} / \mathrm{min}$ for 2 hours.

which prevents $\mathrm{Cu}$ aggregating or deactivation owing to coking. A detailed analysis of the as-grown MWCNTs and amorphous carbon were characterized by TGA and Raman spectra, shown in Figure 3a and 3b, respectively. The TGA oxidation profile of the as-grown MWCNTs and of the amorphous carbon over $5.0 \mathrm{wt} \% \mathrm{CuSO}_{4} / \gamma-\mathrm{Al}_{2} \mathrm{O}_{3}$ catalyst is displayed in Figure 3a. Two peaks are clearly shown in the first-derivative curve of the TGA profile. Accordingly, the low-temperature peak $\left(446{ }^{\circ} \mathrm{C}\right)$ is assigned to the combustion of amorphous carbon and the higher temperature $\left(515^{\circ} \mathrm{C}\right)$ is assigned to that of MWCNTs ${ }^{16,17}$. The growth yield of the as-grown carbon soot is approximately 30.4 wt $\%$ with a composition of approximately $44 \%$ amorphous carbon and 56\% MWCNTs. The graphitic quality of the asgrown MWCNTs was determined using the intensity ration of the G-band (tangential mode of graphite $1343 \mathrm{~cm}^{-1}$ ) and D-band (defect mode $1600 \mathrm{~cm}^{-1}$ ). Figure $3 \mathrm{~b}$ displays that the $\mathrm{I}_{\mathrm{G}} / \mathrm{I}_{\mathrm{D}}(\sim 1.0)$ ratio is a typical feature of MWCNTs. The yields of the as-grown MWCNTs at various reaction times over $5.0 \mathrm{wt} \% \mathrm{CuSO}_{4} / \gamma-\mathrm{Al}_{2} \mathrm{O}_{3}$ catalyst in NOCM in the initial 150 min was plotted in Figure 3c. A linear relationship between the MWCNT yields and reaction times was observed. Combined with the results in the left-upper panel of Figure 1, it is clearly to note that the growth of MWCNTs is the decisive step in NOCM over $5.0 \mathrm{wt} \% \mathrm{CuSO}_{4} / \gamma-\mathrm{Al}_{2} \mathrm{O}_{3}$ catalyst. The average particle size of $\mathrm{Cu}$ NPs calculated using XRD patterns of $\mathrm{Cu}(111)$ crystalline $\left(2 \theta=43.3^{\circ}\right)$ with various reaction times in NOCM also illustrated in Figure 3d. A slightly raising size of $\mathrm{Cu}$ NPs is not the main factor to dominate the catalytic activity for NOCM.
For NOCM, $\mathrm{CH}_{4}$ conversion, product selectivity and life time are three main factors to evaluate the catalytic performance of $5.0 \mathrm{wt} \% \mathrm{CuSO}_{4} / \gamma-\mathrm{Al}_{2} \mathrm{O}_{3}$ catalyst. In Figure 1, we demonstrate that the life time in NOCM can maintain $200 \mathrm{~h}$ with a slight decay of activity. Figure $4 \mathrm{a}$ describes the trends of $\mathrm{CH}_{4}$ conversions and $\mathrm{C}_{2}^{+}$selectivities $\left(\mathrm{C}_{2} \mathrm{H}_{4}, \mathrm{C}_{2} \mathrm{H}_{6}\right.$, and $\mathrm{C}_{4} \mathrm{H}_{10}$, mainly) with various reaction times in NOCM at $800{ }^{\circ} \mathrm{C}$ over $5.0 \mathrm{wt} \% \mathrm{CuSO}_{4} / \gamma-\mathrm{Al}_{2} \mathrm{O}_{3}$ catalyst. Apparently, the initial $\mathrm{CH}_{4}$ conversion is near $29.8 \%$, however, which descended quickly in $30 \mathrm{~min}$ and maintained at a stable value of $9.8 \%$ after $150 \mathrm{~min}$ testing time. Selectivity to ethylene plus ethane $(78.2 \%)$, and butadiene (1.6\%) were constant while the reaction time was above 150 minutes. Although activity and conversion of NOCM over $5 \mathrm{wt} \% \mathrm{CuSO}_{4} /$ $\gamma-\mathrm{Al}_{2} \mathrm{O}_{3}$ is not the highest compared with previous reports ${ }^{1,}$ ${ }^{2}$, however, the formation of carbon-related materials didn't obey the previous concept as a role of deactivation for NOCM. On the contrary, the as-grown carbon-related materials dominated the reaction process in NOCM. By comparison, the pretreatments of $5.0 \mathrm{wt} \% \mathrm{CuSO}_{4} / \gamma-\mathrm{Al}_{2} \mathrm{O}_{3}$ catalyst were conducted at $800{ }^{\circ} \mathrm{C}$ under air, argon diluted hydrogen, or helium for 2 hours, the results are presented in Figure 4b I-III, respectively. Interestingly, under helium or hydrogen treatments, the maximum activities would reach in less 100 minutes, however their highest catalytic rates are still lower than that of air-treated sample. The major difference on these treatments was the formation of $\mathrm{Cu}$ nanoparticles (NPs). Calculated by XRD patterns of $\mathrm{Cu}$ (111) using Scherrer equation, the particle sizes of $\mathrm{Cu}$ NPs by helium and hydrogen pretreatments are 27.2 and 32.5 

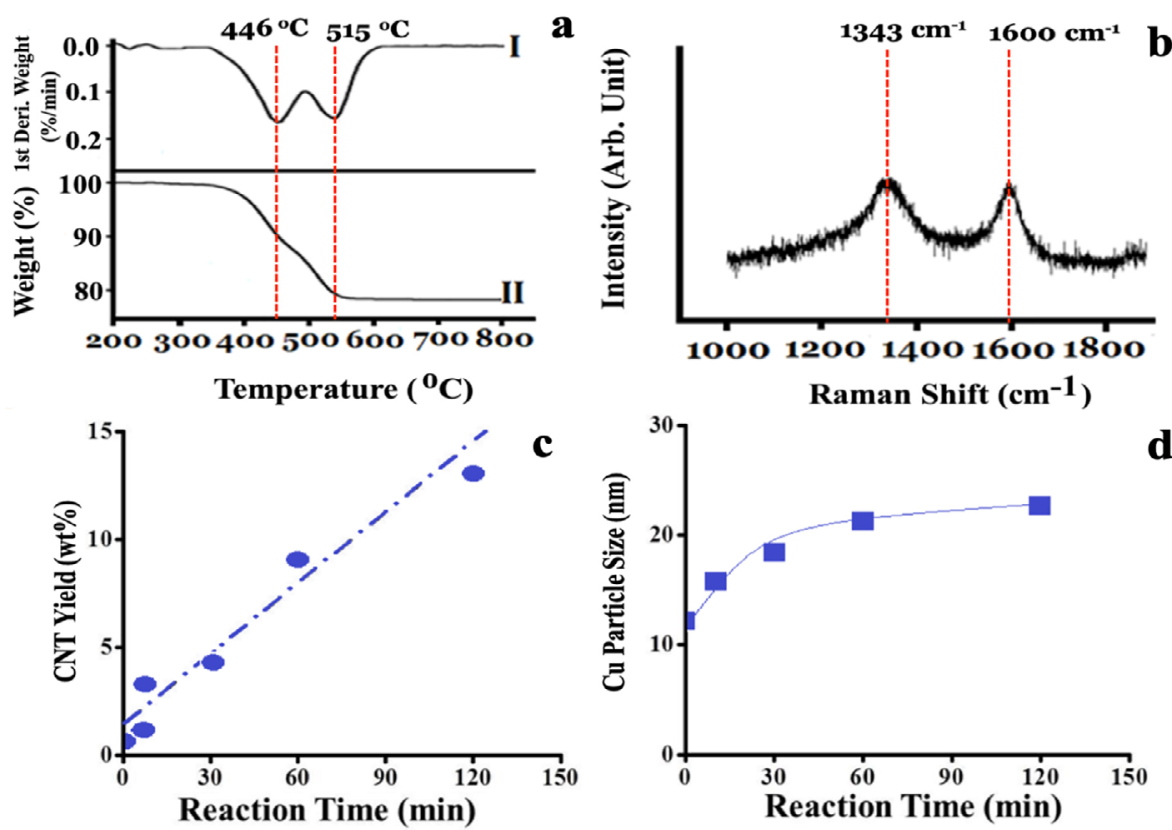

Figure 3. (a) Oxidative TGA profiles and (b) Raman spectra of the samples over $5.0 \mathrm{wt} \% \mathrm{CuSO}_{4} / \gamma-\mathrm{Al}_{2} \mathrm{O}_{3}$ catalyst in NOCM at $800{ }^{\circ} \mathrm{C}$ under a mixture of Ar diluted methane with a flow rate of $40 \mathrm{~mL} / \mathrm{min}$ for 2 hours. (c) the CNT yield versus the reaction time over $5.0 \mathrm{wt} \% \mathrm{CuSO}_{4} / \gamma-\mathrm{Al}_{2} \mathrm{O}_{3}$ catalyst in NOCM at $800{ }^{\circ} \mathrm{C}$ under a mixture of Ar diluted methane with a flow rate of $40 \mathrm{~mL} / \mathrm{min}$. (d) the average particle size of Cu NPs calculated through XRD patterns of $\mathrm{Cu}$ (111) at $2 \theta=43.3^{\circ}$ based on Scherrer equation.
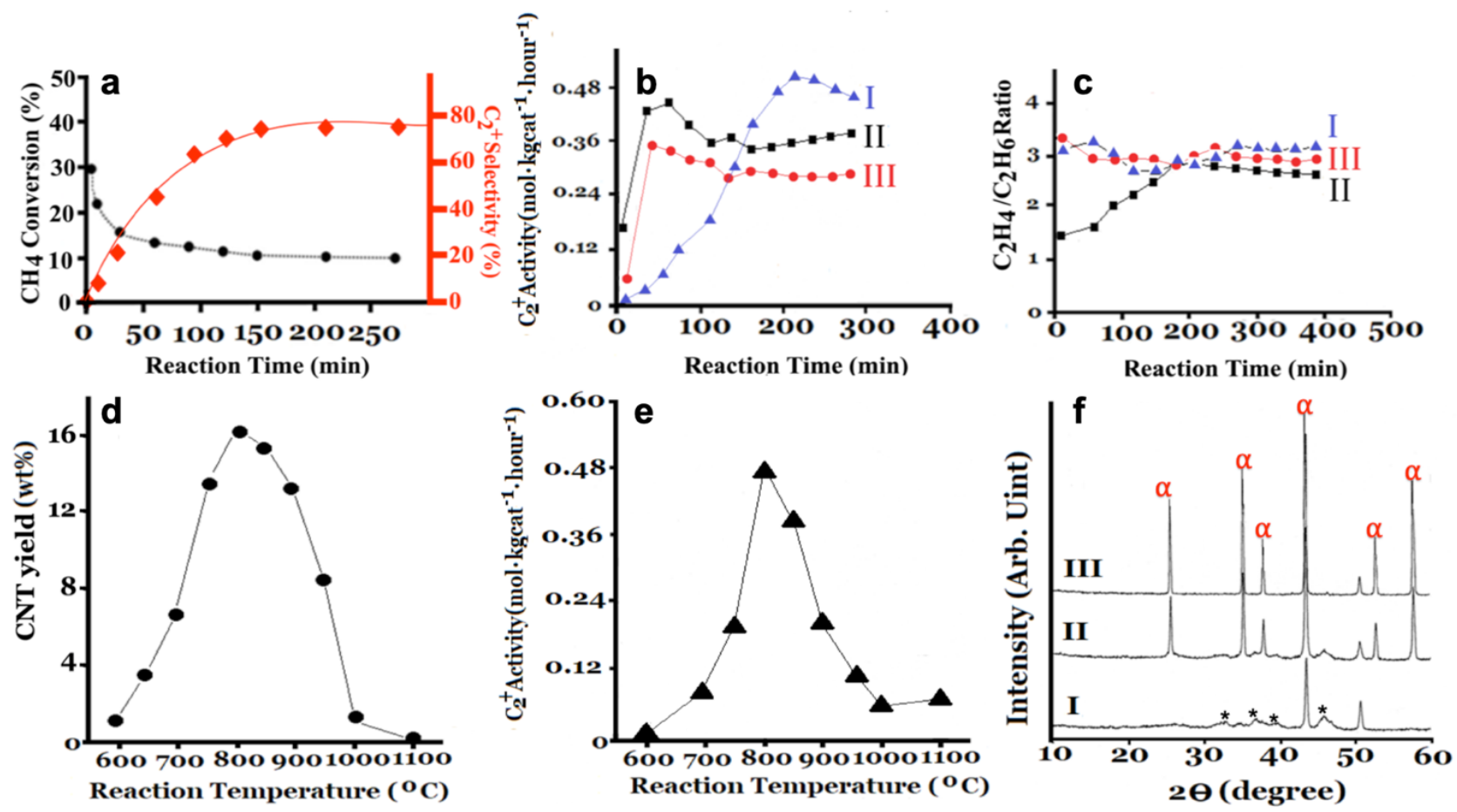

Figure 4. (a) Catalytic performance of $5.0 \mathrm{wt} \% \mathrm{CuSO}_{4} / \gamma-\mathrm{Al}_{2} \mathrm{O}_{3}$ catalyst for $\mathrm{CH}_{4}$ conversion and $\mathrm{C}_{2}^{+}$selectivity in NOCM. (b) $\mathrm{C}_{2}{ }^{+}$activity performance and (c) $\mathrm{C}_{2} \mathrm{H}_{4} / \mathrm{C}_{2} \mathrm{H}_{6}$ yield ratios of (I) Air-treated, (II) $\mathrm{H}_{2} / \mathrm{N}_{2}$ (=1/3)-treated, and (III) He-treated samples of $5.0 \mathrm{wt} \% \mathrm{CuSO}_{4} / \gamma-\mathrm{Al}_{2} \mathrm{O}_{3}$ catalyst at $800{ }^{\circ} \mathrm{C}$ under a mixture of Ar diluted methane with a flow rate of $40 \mathrm{~mL} / \mathrm{min}$. Pretreatment time for (I-III) is 2 hours at $800{ }^{\circ} \mathrm{C}$ with a flow rate of $40 \mathrm{~mL} / \mathrm{min}$. Profiles of (d) CNT yields and (e) $\mathrm{C}_{2}{ }^{+}$activities $5.0 \mathrm{wt} \% \mathrm{CuSO}_{4} / \gamma-\mathrm{Al}_{2} \mathrm{O}_{3}$ catalyst at various reaction temperatures in NOCM under a mixture of Ar diluted methane with a flow rate of $40 \mathrm{~mL} / \mathrm{min}$. (f) $\mathrm{XRD}$ patterns of $5.0 \mathrm{wt} \% \mathrm{CuSO}_{4} / \gamma-\mathrm{Al}_{2} \mathrm{O}_{3}$ catalyst at (I) 800, (II) 1000 , and (III) $1100{ }^{\circ} \mathrm{C}$.

$\mathrm{nm}$, respectively. This perhaps explains why the catalytic activity in NOCM, air-treated sample is highest, owing to slow formation of $\mathrm{Cu}$ NPs under methane. The Cu NPs are easily to aggregate during the reaction temperature and reduced its activity. Furthermore, the aggregation of Cu NPs will retard the formation of carbon nanotubes, therefore lower down the catalytic activity in NOCM. Although the various treatments will cause the different catalytic performances, however if the promoted effect should come from the as-grown MWCNTs. The products of ethylene/ethane ratios would be similar in the stable catalytic reaction, Figure $4 \mathrm{c}$ supports our consideration. The catalytically initiat- 

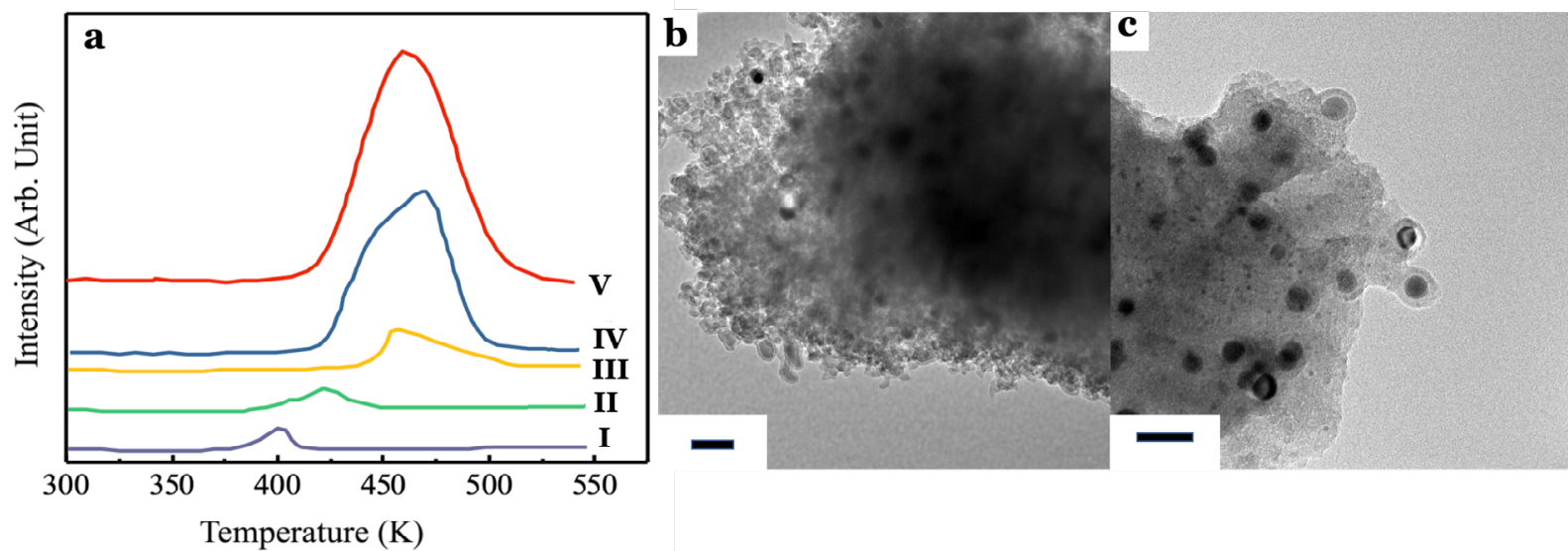

Figure 5. (a) Temperature programmed reduction profiles of $5.0 \mathrm{wt} \% \mathrm{Cu} / \gamma-\mathrm{Al}_{2} \mathrm{O}_{3}$ catalysts with various $\mathrm{Cu}$ precursors (I) $\mathrm{Cu}\left(\mathrm{CH}_{3} \mathrm{COO}\right)_{2}$, (II) $\mathrm{Cu}\left(\mathrm{NO}_{3}\right)_{2}$, and (III) $\mathrm{CuSO}_{4}$. A comparison TPR profiles of (IV) Air-treated bulk CuO and (V) untreated bulk $\mathrm{CuO}$ powder. (b) and (c) are the typical TEM images of samples, $5.0 \mathrm{wt} \% \mathrm{Cu} / \gamma-\mathrm{Al}_{2} \mathrm{O}_{3}$ catalysts prepared with $\mathrm{Cu}(\mathrm{CH}$ $\left.{ }_{3} \mathrm{COO}\right)_{2}$, and $\mathrm{Cu}\left(\mathrm{NO}_{3}\right)_{2}$, respectively, in NOCM at $800{ }^{\circ} \mathrm{C}$ under a mixture of Ar diluted methane with a flow rate of $40 \mathrm{~mL} /$ min for 2 hours.
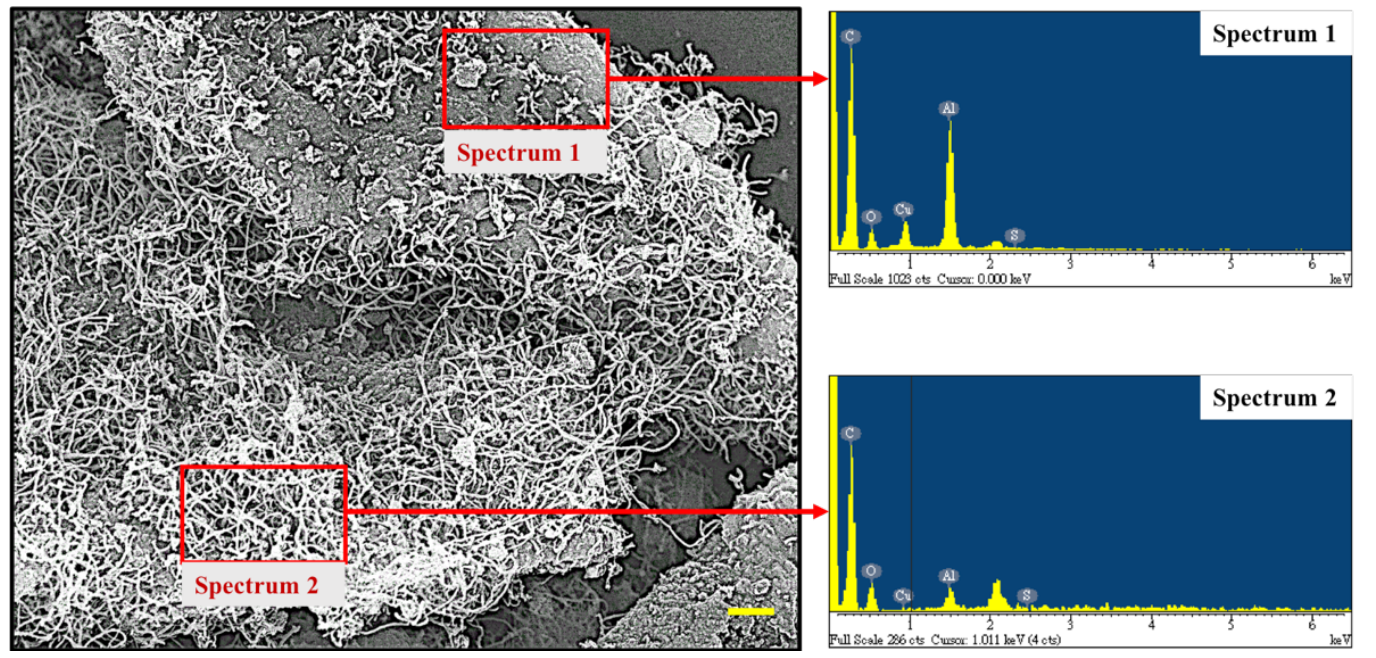

\begin{tabular}{|c|c|}
\hline Element & Weight $\%$ \\
\hline C K & 70.28 \\
\hline O K & 10.52 \\
\hline Al K & 11.64 \\
\hline S k & 0.06 \\
\hline Cu L & 7.50 \\
\hline Totals & 100 \\
\hline
\end{tabular}

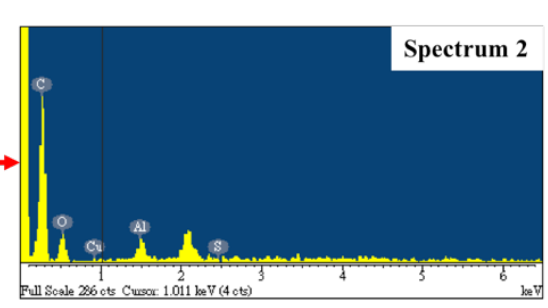

\begin{tabular}{|c|c|}
\hline Element & Weight\% \\
\hline C K & 70.07 \\
\hline O K & 25.58 \\
\hline Al K & 3.25 \\
\hline S k & 0.32 \\
\hline Cu L & 0.78 \\
\hline Totals & 100 \\
\hline
\end{tabular}

Figure 6. EDS spectra and semi-quantitatively elemental analysis of the two selected area of a typical SEM image of 5.0 wt $\% \mathrm{CuSO}_{4} / \gamma-\mathrm{Al}_{2} \mathrm{O}_{3}$ catalyst in NOCM at 800 under a mixture of Ar diluted methane with a flow rate of $40 \mathrm{~mL} / \mathrm{min}$ for 2 hours.

ed reaction was caused by $\mathrm{Cu} \mathrm{NPs}$ or $\mathrm{CuO}$, so the ethylene/ ethane ratios are varying in the beginning, however, the ratios will get to the similar values at about 3.0 after 200 -minute reaction time. For understanding the promoted effect of the as-grown CNTs, we conducted the NOCM on $5.0 \mathrm{wt} \%$ $\mathrm{CuSO}_{4} / \gamma-\mathrm{Al}_{2} \mathrm{O}_{3}$ with various temperatures $\left(600-1100{ }^{\circ} \mathrm{C}\right)$. The results were displayed in Figure 4d-4e. Interestingly, the maximum yield (16.8 wt\%) of CNTs (Figure $4 \mathrm{~d}$ ) was occurred at $800{ }^{\circ} \mathrm{C}$, which also performed the highest activity of NOCM, shown in Figure 4e. The trend of catalytic activity is consistent with that of the deposited amount of CNTs, which depicts that the catalytic performance of 5.0 wt $\% \mathrm{CuSO}_{4} / \gamma-\mathrm{Al}_{2} \mathrm{O}_{3}$ would be promoted by the as-grown CNTs. The decay of activity while the reaction temperature was higher than $800{ }^{\circ} \mathrm{C}$ was examined by XRD patterns, shown in Figure $4 \mathrm{f}$. The possible reason is that the support- $\mathrm{Al}_{2} \mathrm{O}_{3}$ will transform from $\gamma$ to $\theta$ form, and then finally become the $\alpha$ form when temperature increased above $800{ }^{\circ} \mathrm{C}$. The crystallinity of $\alpha-\mathrm{Al}_{2} \mathrm{O}_{3}$ display higher integrity and also indicates that the surface area of $\mathrm{Al}_{2} \mathrm{O}_{3}$ will highly reduce from $\gamma$ to $\alpha$ form. Therefore, the intensely aggregation of $\mathrm{Cu}$ NPs will happen, this accelerates the deactivation of catalytic activity in NOCM. This demonstrate a new concept that the in-situ growth of CNTs displays an unexpectedly promoting effect for NOCM over $5.0 \mathrm{wt} \% \mathrm{CuSO}_{4} / \gamma-\mathrm{Al}_{2} \mathrm{O}_{3}$ catalyst.

Apart from the catalytic performances of $5.0 \mathrm{wt} \% \mathrm{CuSO}_{4} /$ $\gamma-\mathrm{Al}_{2} \mathrm{O}_{3}$ catalyst for NOCM, it is essential to investigate the active components of $5.0 \mathrm{wt} \% \mathrm{CuSO}_{4} / \gamma-\mathrm{Al}_{2} \mathrm{O}_{3}$ catalyst. In Figure 2, we note that metallic $\mathrm{Cu}$ NPs should be active centers for growing CNTs and promote the transformation of $\mathrm{CH}_{4}$ into light olefins, e.g. $\mathrm{C}_{2} \mathrm{H}_{6}, \mathrm{C}_{2} \mathrm{H}_{4}$...etc., in NOCM. Therefore, we prepared several $\mathrm{Cu}$ catalysts using various $\mathrm{Cu}$ precursors, such as $\mathrm{Cu}\left(\mathrm{CH}_{3} \mathrm{COO}\right)_{2}$ and $\mathrm{Cu}\left(\mathrm{NO}_{3}\right)_{2}$, supported on $\gamma-\mathrm{Al}_{2} \mathrm{O}_{3}$ through impregnation. The temperature-programmed reduction profiles of $\mathrm{Cu}$-based catalysts are shown in Figure 5a. Obviously, $\mathrm{Cu}$ catalysts prepared by $\mathrm{Cu}\left(\mathrm{CH}_{3} \mathrm{COO}\right)_{2}$ (Figure 5a-I) and $\mathrm{Cu}\left(\mathrm{NO}_{3}\right)_{2}$ (Figure 5aII) display reduction peaks at lower temperatures which are assigned to smaller $\mathrm{CuO} \mathrm{NPs}$. $\mathrm{CuSO}_{4}{ }^{-}$derived $\mathrm{Cu}$ catalyst (Figure 5a-III) conducts similar TPR peak comparing with those of bulk $\mathrm{CuO}$ (Figure 5a-V) or air-treated $\mathrm{CuO}$ (Figure 5a-IV). However, $\mathrm{Cu}$ catalysts derived from $\mathrm{Cu}(\mathrm{CH}-$ $\left.{ }_{3} \mathrm{COO}\right)_{2}, \mathrm{Cu}\left(\mathrm{NO}_{3}\right)_{2}$, or bulk $\mathrm{CuO}$ did not show any catalytic activities in NOCM. Figure 5b-5c demonstrate clear images that $\mathrm{Cu}$ catalysts-derived from $\mathrm{Cu}\left(\mathrm{CH}_{3} \mathrm{COO}\right)_{2}$ or $\mathrm{Cu}(-$ 
$\left.\mathrm{NO}_{3}\right)_{2}$ will deactivate quickly. The main reason is that $\mathrm{Cu}$ NPs were coated with amorphous carbon through the over dehydrogenation of methane. Interestingly, why $\mathrm{CuSO}_{4} /$ $\gamma-\mathrm{Al}_{2} \mathrm{O}_{3}$ catalyst can survive and conduct remarkable catalytic performance in NOCM. The ruling difference is the strong metal-support interaction (SMSI) between $\mathrm{CuSO}_{4}$ and $\gamma-\mathrm{Al}_{2} \mathrm{O}_{3}{ }^{16,17}$, which dominates the growth of CNTs and then promotes the activity in NOCM. Without SMSI, $\mathrm{Cu}$ NPs which derived from $\mathrm{Cu}\left(\mathrm{CH}_{3} \mathrm{COO}\right)_{2}$ or $\mathrm{Cu}\left(\mathrm{NO}_{3}\right)_{2}$ are easy to aggregate and then covered with amorphous carbon. This will cause the deactivation of catalytic activity very soon, usually in several minutes.

In order to testify our consideration, we examine surface morphologies of $\mathrm{CuSO}_{4} / \gamma-\mathrm{Al}_{2} \mathrm{O}_{3}$ catalyst which conducted the NOCM for 120 min, shown in Figure 6. The SEM image demonstrates dense-growth CNTs and CNT-free area on $\mathrm{CuSO}_{4} / \gamma-\mathrm{Al}_{2} \mathrm{O}_{3}$ catalyst. Semi-quantitatively elemental analysis of two areas using EDX spectra (spectrum 1 and spectrum 2) are listed. It is obviously to note that CNTfree area presents lower values of $\mathrm{S}$ and $\mathrm{O}$ elements, which strongly suggests that $\mathrm{SO}_{\mathrm{x}}$ is the determining component of $\mathrm{CuSO}_{4} / \gamma-\mathrm{Al}_{2} \mathrm{O}_{3}$ catalyst.

Our observations reveal that the switch from OCM to NOCM over $5.0 \mathrm{wt} \% \mathrm{CuSO}_{4} / \gamma-\mathrm{Al}_{2} \mathrm{O}_{3}$ catalyst will initially generate CNTs instead of conducting the coupling of methane. Therefore, the reactivity of catalyst was quickly dropping to zero, and further instrumentally examined owing to the formation of CNTs. Possibly, this is the main reason why previously studies on NOCM did not disclose the promoting effect of the as-grown carbon materials. In this work, we reveal that the catalytic reactivity will recover gradually in NOCM using $5.0 \mathrm{wt} \% \mathrm{CuSO}_{4} / \gamma-\mathrm{Al}_{2} \mathrm{O}_{3}$ catalyst with adequate reaction time. As examining the results shown from Figure 1 to Figure 6, we can suppose that the unexpected promoting effect of the as-grown MWCNTs were performed with two stages. MWCNTs were formed in the initial stage of the dehydrogenation of methane through a surface-diffusion mode over copper nanoparticles in $5.0 \mathrm{wt} \% \mathrm{CuSO}_{4} / \gamma-\mathrm{Al}_{2} \mathrm{O}_{3}$ catalyst. Then $\mathrm{Cu}$ NPs were highly dispersed on the top of the tangle-like MWCNTs, which mainly conducted the route of coupling of methane into ethylene, ethane and higher hydrocarbons. This interesting result was not reported previous.

\section{CONCLUSIONS}

Here, we demonstrate $5.0 \mathrm{wt} \% \mathrm{CuSO}_{4} / \gamma-\mathrm{Al}_{2} \mathrm{O}_{3}$ catalyst can perform both OCM and NOCM. The maximum activity of NOCM is near twice of that for OCM. The as-grown MWCNTs is firstly reported to be unexpected promoter for $5.0 \mathrm{wt} \% \mathrm{CuSO}_{4} / \gamma-\mathrm{Al}_{2} \mathrm{O}_{3}$ catalyst in NOCM. The yield of the activity is 0.48 mol kgcat $^{-1}$ hour ${ }^{-1}$ with a $\mathrm{C}_{2}$ selectivity of $78.2 \%$ and an equilibrium methane conversion of $9.8 \%$ at $800{ }^{\circ} \mathrm{C}$. A 200 -h catalytic testing, the activity can maintain at $85 \%$ of the highest value. We explore a new concept for direct converting of methane with the promotion of the asgrown carbon materials instead of deactivation.

\section{Acknowledgements}

This work is supported by the Ministry of Science and Technology of Taiwan. (MOST 104-2113-M-024- and MOST
105-2113-M-024-001).

\section{Notes}

The authors declare no competing financial interest.

\section{References}

[1] Guo X, Fang G, Li G, Ma H, Fan H, Yu L, et al. Direct, Nonoxidative Conversion of Methane to Ethylene, Aromatics, and Hydrogen. Science 2014;344:616-9. doi:10.1126/science.1253150

[2] Morejudo SH, Zanón R, Escolástico S, Yuste-Tirados I, Malerød-Fjeld H, Vestre PK, et al. Direct conversion of methane to aromatics in a catalytic co-ionic membrane reactor. Science 2016;353:563-6. doi:10.1126/science.aag0274

[3] Sheng H, Schreiner EP, Zheng W, Lobo RF. Non-oxidative Coupling of Methane to Ethylene Using Mo2 C/[B]ZSM-5. ChemPhysChem 2018;19:504-11. doi:10.1002/cphc.201701001

[4] KELLER G. Synthesis of ethylene via oxidative coupling of methane I. Determination of active catalysts. Journal of Catalysis 1982;73:9-19. doi:10.1016/0021-9517(82)90075-6

[5] OTSUKA K. Active and selective catalysts for the synthesis of $\mathrm{C}_{2} \mathrm{H}_{4}$ and $\mathrm{C}_{2} \mathrm{H}_{6}$ via oxidative coupling of methane. Journal of Catalysis 1986;100:353-9. doi:10.1016/0021-9517(86)90102-8

[6] Amenomiya Y, Birss VI, Goledzinowski M, Galuszka J, Sanger AR. Conversion of Methane by Oxidative Coupling. Catalysis Reviews 1990;32:163-227. doi:10.1080/01614949009351351

[7] Lunsford JH. The Catalytic Oxidative Coupling of Methane. Angewandte Chemie International Edition in English 1995;34:970-80. doi:10.1002/anie.199509701

[8] Lunsford JH. Catalytic conversion of methane to more useful chemicals and fuels: a challenge for the 21st century. Catalysis Today 2000;63:165-74. doi:10.1016/S0920-5861(00)00456-9

[9] Chen L, Lin L, Xu Z, Zhang T, Li X. Promotional effect of Pt on non-oxidative methane transformation over Mo-HZSM-5 catalyst. Catalysis Letters 1996;39:169-72. doi:10.1007/BF00805578

[10] Soulivong D, Norsic S, Taoufik M, Coperet C, Thivolle-Cazat J, Chakka S, et al. Non-Oxidative Coupling Reaction of Methane to Ethane and Hydrogen Catalyzed by the Silica-Supported Tantalum Hydride: $(\equiv \mathrm{SiO})_{2} \mathrm{Ta}-\mathrm{H}$. Journal of the American Chemical Society 2008;130:5044-5. doi:10.1021/ja800863x

[11] Lukyanov DB, Vazhnova T. Transformation of methane over platinum supported catalysts at moderate temperature. Journal of Molecular Catalysis A: Chemical 2011;342-343:1-5. doi:10.1016/ j.molcata.2011.04.011

[12] Li L, Mu X, Liu W, Kong X, Fan S, Mi Z, et al. Thermal Non-Oxidative Aromatization of Light Alkanes Catalyzed by Gallium Nitride. Angewandte Chemie International Edition 2014;53:14106-9. doi:10.1002/anie.201408754

[13] Nishikawa Y, Ogihara H, Yamanaka I. Liquid-Metal Indium Catalysis for Direct Dehydrogenative Conversion of Methane to Higher Hydrocarbons. ChemistrySelect 2017;2(16):4572-6. http:// doi.org/10.1002/slct.201700734

[14] Gerceker D, Motagamwala AH, Rivera-Dones KR, Miller JB, Huber GW, Mavrikakis M, et al. Methane Conversion to Ethylene and Aromatics on PtSn Catalysts. ACS Catalysis 2017;7:2088-100. doi:10.1021/acscatal.6b02724

[15] Xiao Y, Varma A. Highly Selective Nonoxidative Coupling of Methane over Pt-Bi Bimetallic Catalysts. ACS Catalysis 2018;8:2735-40. doi:10.1021/acscatal.8b00156

[16] Lin Y-C, Lin J-H. Purity-controllable growth of bamboo-like multi-walled carbon nanotubes over copper-based catalysts. Catalysis Communications 2013;34:41-4. doi:10.1016/j.cat- 
com.2013.01.013

[17] Lin J-H, Chen C-S, Zeng Z-Y, Chang C-W, Chen H-W. Sulphate-activated growth of bamboo-like carbon nanotubes over copper catalysts. Nanoscale 2012;4:4757. doi:10.1039/c2nr30854a [18] Murata K, Hayakawa T, Fujita K. Excellent effect of lithium-doped sulfated zirconia catalysts for oxidative coupling of methane to give ethene and ethane. Chemical Communications 1997:221-2. doi:10.1039/a606624k

[19] Kurosaka T, Matsuhashi H, Arata K. Dehydrogenative Coupling of Methane Catalyzed by Platinum-Added Sulfated Zirconia and Characterization of the Catalyst Surface. Journal of Catalysis 1998;179:28-35. doi:10.1006/jcat.1998.2209

[20] Farrell BL, Igenegbai VO, Linic S. A Viewpoint on Direct Methane Conversion to Ethane and Ethylene Using Oxidative Coupling on Solid Catalysts. ACS Catalysis 2016;6:4340-6. doi:10.1021/acscatal.6b01087

[21] Lin J-H, Chen C-S, Ma H-L, Hsu C-Y, Chen H-W. Synthesis of MWCNTs on CuSO4/Al2O3 using chemical vapor deposition from methane. Carbon 2007;45:223-5. doi:10.1016/j.carbon.2006.09.012 [22] Lin J-H, Chen C-S, Rümmeli MH, Zeng Z-Y. Self-assembly formation of multi-walled carbon nanotubes on gold surfaces. Nanoscale 2010;2:2835. doi:10.1039/c0nr00256a

[23] Hsiao C-H, Lin J-H. Growth of a superhydrophobic multiwalled carbon nanotube forest on quartz using flow-vapor-deposited copper catalysts. Carbon 2017;124:637-41. doi:10.1016/ j.carbon.2017.09.023

\section{Open Access}

This article is licensed under a Creative Commons Attribution 4.0 International License.

(c) The Author(s) 2018 